DOI 10.37882/2500-3682.2021.05.10

\title{
СОЦИАЛЬНАЯ ТРЕВОЖНОСТЬ И СОВЛАДАЮЩЕЕ ПОВЕДЕНИЕ У СТУДЕНТОВ ПЕРВОГО КУРСА МЕДИЦИНСКОГО УНИВЕРСИТЕТА
}

\section{SOCIAL ANXIETY AND COORDINATING BEHAVIOR OF FIRST COURSE STUDENTS OF MEDICAL UNIVERSITY \\ O. Gerasimova \\ L. Semchenko S. Batueva}

Summary: The article presents the results of a study of social anxiety and methods of coping with stress in first-year students of a medical university. We used five methods that made it possible to identify the relationship between social anxiety and depression, fear of negative assessment and the choice of coping strategy. It was revealed that more than $30.0 \%$ of students have an average and high level of social anxiety. Every third person has a strong fear of a negative assessment. Strong and very strong social phobia was found in $64.0 \%$ of the surveyed. Depressive symptoms are observed in $44.7 \%$ of students. First-year students quite often resort to non-constructive methods of coping with stress and anxiety.

Keywords: social anxiety, social phobias, coping strategies, students.

\author{
Герасимова Оксана Юрьевна \\ К.б.н., дочент, Южно-Уральский государственный \\ медицинский университет Минздрава России, \\ 2. Челябинск \\ oksana-5858@mail.ru \\ Семченко Любовь Николаевна \\ К.м.н., дочент, Южно-Уральский государственный \\ медицинский университет Минздрава России, \\ 2. Челябинск \\ luba_sem96@mail.ru \\ Батуева Светлана Владимировна \\ К.п.н., дочент, Южно-Уральский государственный \\ медицинский университет Минздрава России, \\ 2. Челябинск \\ batuevas@mail.ru
}

Аннотация: В статье представлены результаты исследования социальной тревожности и способов совладающего поведения со стрессом у студентов первого курса медицинского вуза. Использованы пять методик, которые позволили выявить взаимосвязи социальной тревожности с депрессией, со страхом негативной оценки и выбором копинг-стратегии. Выявлено, что более 30,0\% студентов имеют средний и высокий уровень социальной тревожности. У каждого третьего сильно выражен страх негативной оценки. Сильная и очень сильная социофобия выявлена у 64,0\% обследованных. Депрессивные симптомы наблюдаются у 44,7\% студентов. Студенты первого курса достаточно часто прибегают к неконструктивным способам совладания со стрессом и тревогой.

Ключевые слова: социальная тревожность, социофобии, копинг-стратегии, студенты.

на первом курсе обучения. Обучение на первом курсе вуза, как правило, связано со сменой места жительства, разрушением старой социальной сети, необходимостью устанавливать новые социальные контакты. Кроме того, необходимо справляться с интенсивными учебными нагрузками. Все это может вызвать эмоциональную дезадаптацию и потребовать больших психических затрат.

Социальная тревожность определяется как вид тревожности, триггером которого выступают ситуации социального взаимодействия, а основным содержанием является страх негативной оценки со стороны окружающих [13].

Более половины студентов испытывают симптомы тревоги средней и высокой степени тяжести [2; 9]. Кроме того, выявлено, что студенты используют менее конструктивные способы совладания со стрессом, нежели 
взрослые люди [12].

В связи с этим важно вывить факторы, затрудняющие успешное совладание со стрессом и тревогой в студенческой популяции и, наоборот, факторы, способствующие поддержанию психического здоровья и адаптации на этапе обучения в вузе.

Целью исследования является выявление распространенности социальной тревожности, связи социальной тревожности с депрессией, со стратегией совладания и разработка способов предупреждения социальной тревожности у студентов первого курса медицинского вуза.

\section{ЗаАачи исслеАования}

1. Изучить распространенность социальной тревожности у студентов первого курса медицинского вуза.

2. Выявить связи социальной тревожности и депрессии, социальной тревожности и стратегий совладания со стрессом.

3. Предложить меры, направленные на предупреждение социальной тревожности и дезадаптации у студентов первого курса медицинского вуза.

\section{Характеристика выборки и методов исслеАования}

В исследовании приняли участие 60 (32,0\% генеральной совокупности) студентов первого курса педиатрического факультета Южно-Уральского государственного медицинского университета (ЮУГМУ).

Для решения поставленных задач использовались следующие методики:

1. «Опросник тревоги А.Т. Бека» («ВАІ»; разработан А.Т. Весk с соавт., адаптация Н.В. Тарабриной) [15].

2. «Опросник депрессии А.Т. Бека» («BDI»; разработан А.Т. Beck с соавт., адаптация Н.В. Тарабриной) [15].

3. «Шкала страха негативной оценки (Fear of Negative Evaluation)» («FNE»; разработана D. Watson, R. Friend) [16].

4. «Шкала социальной тревожности Либовица» («LSAS»; разработана Liebowitz, 1987, адаптация И.В. Григорьевой, С.Н. Ениколоповым) [8].

5. «Шкала СОРЕ» («СОРE Inventory»; разработана C.S. Carver, M.F. Scheier, J.K. Weintraub) [18].

Bce пункты шкал заполнялись студентами в ходе опроса на практических занятиях. На процедуру обследования от студентов взято добровольное информированное согласие. Исследование проводилось в первом семестре на базе учебной лаборатории патопсихологической диагностики и психотерапии кафедры Психологии ФГБОУ ВО ЮУГМУ Минздрава России.
Надежность и достоверность данных, полученных при исследовании, обеспечивается репрезентативностью выборки и применением апробированных и валидных методик. Статистическая обработка полученных данных проведена методами непараметрической статистики. Для определения корреляционных связей использовался коэффициент Спирмена.

Практическая значимость исследования заключается в том, что полученные данные могут быть использованы для проведения профилактической работы, направленной на коррекцию тревожности студентов и организацию мероприятий, направленных на повышение адаптации к учебной деятельности.

\section{Результаты исследования и их обсужление}

Как видно из таблицы 1, более трети студентов имеют повышенный уровень социальной тревожности, у каждого пятого студента отмечен средний уровень, у каждого десятого - высокий.

Таблица 1.

Распределение студентов с разным уровнем социальной тревожности

\begin{tabular}{|l|c|c|}
\multicolumn{1}{|c|}{ Группы испытуемых } & \multicolumn{1}{|c|}{$\begin{array}{c}\text { Количество } \\
\text { студентов }\end{array}$} & $\begin{array}{c}\text { Удельный вес } \\
(\%)\end{array}$ \\
\hline $\begin{array}{l}\text { Низкий уровень социальной } \\
\text { тревожности }\end{array}$ & 41 & 68,3 \\
\hline $\begin{array}{l}\text { Средний уровень социальной } \\
\text { тревожности }\end{array}$ & 13 & 21,7 \\
\hline $\begin{array}{l}\text { Высокий уровень социальной } \\
\text { тревожности }\end{array}$ & 6 & 10,0 \\
\hline
\end{tabular}

Наши данные отличаются от результатов, полученных при исследовании студентов младших курсов высшего учебного заведения Москвы [11; 14]. Авторами данного исследования выявлено, что среди студентов 1 - 3 курсов более половины имеют средний и высокий уровень социальной тревожности. Таким образом, в исследуемой нами выборке студентов первого курса медицинского университета более высокий уровень эмоционального благополучия. Может быть, это объясняется тем, что к старшим курсам появляются другие факторы, влияющие на уровень тревоги: совмещение учебы с работой, взаимоотношения с противоположным полом, некоторые студенты уже имеют семью, тогда как на первом курсе наибольшую тревогу вызывают ситуации, связанные с учебой и межличностными взаимоотношениями в группе.

Категория студентов с повышенным уровнем тревожности представляет группу риска, так как при осложнении ситуации или появлении дополнительных трудностей возможно появление депрессии и дезадаптации. 
На уровень социальной тревожности влияет страх негативной оценки. Выявлено, что сильно выражен страх негативной оценки у каждого третьего (29,8\%) студента первого курса. Вероятно, в семьях этих студентов есть факторы социальной тревожности, к каковым могут быть отнесены склонность родителей к критике ребенка за допущенные ошибки, сверхвключенность родителей в жизнь ребенка, гиперопека, тем самым родители не дают ребенку проявить самостоятельность и приобрести собственные навыки. В связи с этим может проявиться страх негативной оценки со стороны одногруппников. Страх негативной оценки может быть связан с излишней требовательностью преподавателей.

Эту группу студентов также можно и нужно отнести к группе риска, так как сильно выраженный страх негативной оценки со стороны родителей, педагогов и одногруппников может повлечь за собой эмоциональный паттерн тревоги и депрессии, что в дальнейшем может сказаться на адаптации к учебному процессу.

Высокий уровень страха негативной оценки статистически значимо коррелирует с социальной тревогой (таб. 2).

Таблица 2.

Взаимосвязь страха негативной оценки с социальной тревогой

\begin{tabular}{|l|l|l|} 
& Социальная тревога & $\begin{array}{c}\text { Вероятность ошибки } \\
\text { по R - критерию } \\
\text { Спирмена }\end{array}$ \\
\hline Страх негативной оценки & 0,38 & $P<0,01$ \\
\hline
\end{tabular}

Если страх перед попаданием и пребыванием в социально значимых ситуациях становится постоянным или повторяющимся, то можно говорить о таком явлении как социофобия. Тревога, возникающая при социофобии, воспринимается как неконтролируемая.

По результатам нашего исследования, только у каждого десятого респондента социофобия выражена слабо. Сильная и очень сильная социофобия выявлена у 64,0\% обследованных. Каждый четвертый имеет достаточно выраженную социофобию (рис. 1)

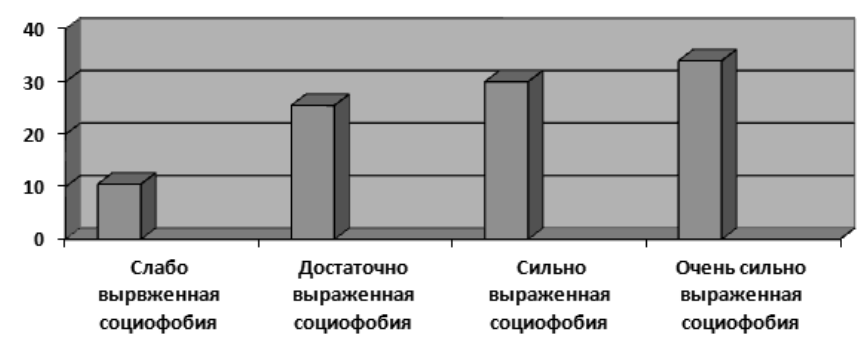

Рис. 1. Распределение студентов по выраженности с оциофобии
Студенты с выраженной социофобией могут запрещать себе действия, в которых, как они полагают, будут смущаться или проявят публично признаки своего беспокойства.

Таким образом почти 90,0\% студентов первого курса медицинского университета, выбрав публичную профессию врача, боятся или избегают видов деятельности, связанных с пребыванием на публике, что может привести к социальной изоляции, одиночеству и депрессии.

Выявлено, что депрессивные симптомы наблюдаются у 44,7\% студентов 1 курса педиатрического факультета. По результатам исследования студентов третьего курса в различных московских вузах симптомы депрессии отмечают у себя 30,0\% [11]. Большее количество студентов с симптомами депрессии по результатам нашего исследования, может быть связано с тем, что студенты первого курса, в отличие от третьего и более старших курсов, еще не адаптировались к новым условиям и требованиям высшей школы.

Симптомы депрессии умеренной степени тяжести отмечают у себя 12,7\% студентов, выраженной степени 4,3\% и у каждого третьего-четвертого - легкая степень депрессии.

Результаты корреляционного анализа по критерию Спирмена свидетельствуют о слабой прямой связи $(0,14)$ показателей социальной тревожности и депрессии при $\mathrm{p}<0,05$.

Для студентов первого курса медицинского университета характерен высокий уровень стресса и тревожные расстройства, особенно в период экзаменационной сессии [4]. В связи с этим эмоциональное благополучие в значительной степени связано с выбором эффективных копинг-стратегий.

Для изучения способов совладания с социальной тревожностью использовалась шкала СОРЕ («COPE Inventory»; разработана C.S.Carver, M.F.Scheier, J.K.Weintraub).

Шкала СОРЕ содержит 15 основных шкал, которые подразделяются на 8 конструктивных и 7 неконструктивных.

На рисунке 2 видно, что из семи неконструктивных стратегий поведения респонденты выбрали пять. Две трети респондентов прибегают к стратегии подавления конкурирующей деятельности. Стратегия направлена на избегание отвлечения другими видами активности и, возможно, игнорирование других видов деятельности. Можно предположить, что студенты первого курса вынуждены выбирать учебную деятельность, отказываясь 
от других, более интересных, по их мнению, видов деятельности.

Это приводит к нарастанию депрессии, проявлению негативных эмоций, и, как следствие, - к дезадаптации. Более половины студентов первого курса используют дезадаптирующие стратегии отрицания и «фокусировка на эмоциях и их вентилирование». Почти такое же количество респондентов прибегают к стратегии самоограничения. Данная стратегия направлена на ожидание подходящего для действий момента и воздержание от слишком поспешных действий. К психологическому избеганию неприятных эмоций прибегают 46,8\% респондентов. Стратегия направлена на использование различных видов активности для отвлечения от неприятных мыслей, связанных с проблемой, которая может повлиять на адаптацию.

Таким образом, студенты первого курса медицинского университета достаточно часто прибегают к неконструктивным способам совладания со стрессом и тревогой, что согласуется с исследованиями других авторов $[11 ; 12]$.

В таблице 3 представлена взаимосвязь социальной тревоги с копинг- стратегиями.

Таблица 3.

Взаимосвязь неконструктивных стратегий совладающего поведения («Шкала СОРЕ») с социальной тревожностью (опросник тревоги А.Т. Бека)

\begin{tabular}{|l|c|c|}
\multicolumn{1}{|c|}{ Копинг-стратегии } & $\begin{array}{c}\text { Социальная } \\
\text { тревога }\end{array}$ & $\begin{array}{c}\text { Вероятность ошибки } \\
\text { по } \mathrm{R} \text { - критерию } \\
\text { Спирмена }\end{array}$ \\
\hline $\begin{array}{l}\text { Фокусировка на неприятных } \\
\text { эмоциях }\end{array}$ & 0,14 & $\mathrm{P}<0,01$ \\
\hline Отрицания & $-0,3$ & $\mathrm{P}<0,01$ \\
\hline Самоограничение & 0,12 & $\mathrm{P}<0,01$ \\
\hline $\begin{array}{l}\text { Подавление конкурирующей } \\
\text { деятельности }\end{array}$ & $-0,21$ & $\mathrm{P}<0,01$ \\
\hline Психологическое избегание & 0,2 & $\mathrm{P}<0,01$ \\
\hline
\end{tabular}

Из восьми предложенных конструктивных стратегий поведения студенты выбрали только четыре (рисунок 3).

Как видно из данных, представленных на рисунке, чаще всего студенты прибегают к активному копингу, который направлен на преодоление стрессовой ситуа-

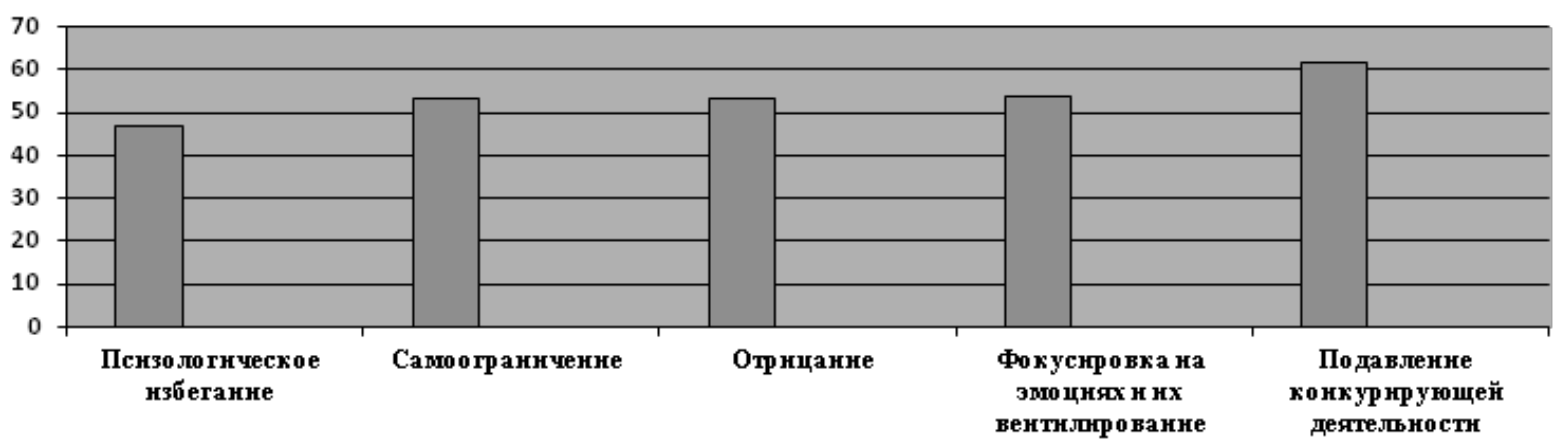

Рис. 2. Показатели выбора неконструктивных стратегий совладающего поведения («Шкала СОРЕ»)

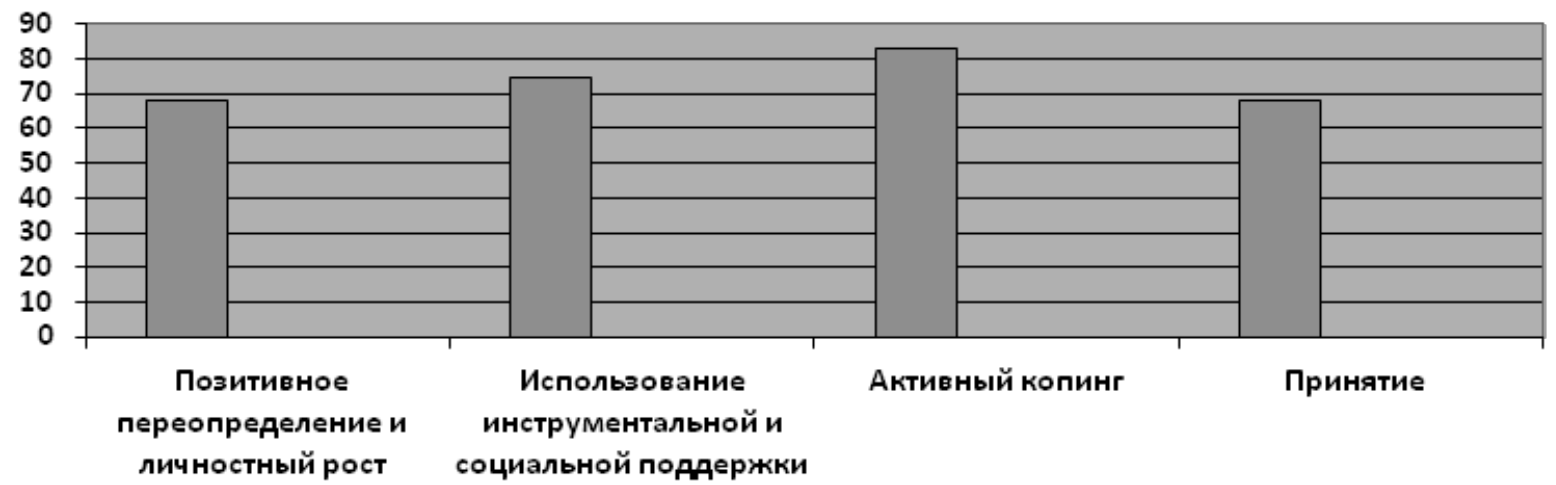

Рис. 3. Показатели выбора конструктивных стратегий совладающего поведения («Шкала СОРЕ») 
ции. На втором месте стратегия инструментальной социальной поддержки, которая направлена на стремление получить совет, помощь или информацию. Практически такое же количество студентов выбирает стратегию, направленную на переопределение и личностный рост, то есть попытка переосмыслить стрессовую ситуацию в позитивном ключе. Две трети респондентов принимают реальность произошедшего.

В таблице 4 представлены только достоверные корреляционные связи между социальной тревогой и конструктивными копинг-стратегиями.

Таблица 4. Взаимосвязь конструктивных стратегий совладающего поведения («Шкала СОРЕ») с социальной тревожностью (опросник тревоги А.Т. Бека)

\begin{tabular}{|l|c|c|}
\multicolumn{1}{|c|}{ Копинг-стратегии } & $\begin{array}{c}\text { Социальная } \\
\text { тревога }\end{array}$ & $\begin{array}{c}\text { Вероятность ошибки } \\
\text { по R - критерию } \\
\text { Спирмена }\end{array}$ \\
\hline Активный копинг & $-0,16$ & $\mathrm{P}<0,01$ \\
\hline $\begin{array}{l}\text { Позитивное переопределение } \\
\text { и личностный рост }\end{array}$ & $-0,17$ & $\mathrm{P}<0,01$ \\
\hline
\end{tabular}

Таким образом, полученные результаты говорят о том, что студенты первого курса медицинского вуза с социальной тревожностью чаще прибегают к неконструктивным способам совладающего поведения.

\section{Выводы}

Более 30,0\% студентов первого курса медицинского вуза имеют средний и высокий уровень социальной тревожности.

У каждого третьего студента первого курса сильно выражен страх негативной оценки, который достоверно коррелирует с социальной тревожностью.

Сильная и очень сильная социофобия выявлена у 64,0\% обследованных.

Депрессивные симптомы наблюдаются у 44,7\% обследованных студентов в том числе у 17,0\% студентов отмечаются симптомы депрессии умеренной и выраженной степени тяжести.

Студенты первого курса медицинского университета достаточно часто прибегают к неконструктивным способам совладания со стрессом и тревогой.

Из конструктивных способов совладания со стрессом и тревожностью студенты чаще прибегают к активному копингу и стратегии позитивного переопределения и личностного роста, которые имеют достоверные корре- ляционные связи с социальной тревожностью.

Таким образом, проведенное исследование в очередной раз подтвердило результаты ранее проведенных нами исследований и исследований других авторов, что среди студентов медицинского вуза высокая распространенность различных тревожных расстройств, и что современное состояние психического здоровья и социальной адаптации студентов требуют активизации профилактики психических и социоадаптивных отклонений и нарушений. Особенно это касается студентов первого курса, значительная часть которых тяжело адаптируется к новым условиям и требованиям высшей школы и у которых уже к концу первого семестра отмечены различные тревожные расстройства. Высокий уровень тревоги негативно сказывается не только на качестве жизни индивида, но в студенческой среде влияет на взаимодействие с одногруппниками и преподавателями, а в дальнейшем может негативно сказаться на общении с пациентами.

\section{РекоменАашии}

Первичная профилактика невротических расстройств в процессе учебной деятельности у студентов медицинского вуза должна быть направлена на предупреждение возникновения стресса и напряжения посредством создания благоприятного психологического климата в процессе общения между преподавателем и студентом, предъявление разумных педагогических требований, обеспечение обратной связи в процессе обучения, продуманный отбор учебного материала, соответствующий актуальным потребностям студента.

Более широко проводить психологическую диагностику личностных особенностей студента. На основе знания и учета индивидуальных личностных особенностей студентов, куратор (в качестве такового могут выступать преподаватели кафедр Психологии и Клинической психологии и социальной работы, а также студенты старших курсов факультета клинической психологии и социальной работы) выбирает и осуществляет требуемые психолого-педагогические воздействия в каждом конкретном случае.

Для характеристики параметров психологического здоровья студентов целесообразно проводить периодические социологические опросы с включением в них вопросов по самооценке здоровья и параметров поведенческих факторов. Организовать, обеспечить и проводить мониторинг состояния здоровья студентов мог бы специалист, владеющий сестринским процессом, основами психологии и педагогики на кафедре сестринского дела и ухода за больными.

Целесообразно оптимизировать врачебно-профес- 
сиональное консультирование молодых людей непосредственно перед выбором вуза или специальности, базой для этого может служить учебная лаборатория патопсихологической диагностики и психотерапии кафедры Психологии ФГБОУ ВО ЮУГМУ и студенческая поликлиника.

\section{ЛИТЕРАТУРА}

1. Гаранян Н.Г., Андрусенко Д.А., Хломов И.Д. Перфекционизм как фактор студенческой дезадаптации //Психологическая наук и 0бразование. 2009. - №3. C. $72-81$

2. Гаранян, Н.Г., Холмогорова А.Г., Евдокимова Я.Г., Москова М.В. и др. Предэкзаменационный стресс и эмоциональная дезадаптация у студентов младших курсов // Социальная и клиническая психиатрия. 2007. - № 2. С. 38 - 43

3. Герасимова 0.Ю., Маркина А.Ю. Эмоционально -психологические отклонения в здоровье студентов на этапе получения ими образования // Теория и практика современной науки. 2017. - № 1 (19). С. 251 - 254.

4. Герасимова 0.Ю., Семченко Л.Н. Тревожные расстройства у студентов медицинского университета // Психология. Психофизиология. 2020. Т. 13. - № 4. С. $30-38$

5. Герасимова 0.Ю., Семченко Л.Н., Никонов А.С. Психологические особенности суицидального поведения в подростковом возрасте // Девиантология. 2019. T, 3. - № 1. С. 37 - 43

6. Горшков Е.А., Коротина Л.Д. Исследование эмоциональной тревожности студентов на разных этапах обучения в педагогическом вузе // Молодой ученый. 2015. - № 23.2 (103.2). С. 46 - 51.

7. Григорьева И.В., Ениколопов С.Н. Апробация опросников «Шкала социальной тревожности Либовица» и ШШкала страха негативной оценки (краткая версия)» // Национальный психологический журнал. 2016. - № 1(21). С. 31 - 44.

8. Евдокимова Я.Г. Интерперсональные факторы эмоциональной дезадаптации у студентов младших курсов // Психологическая наука и образование. 2007 .T. 12, - №5. С.71- 81

9. Кошелева Е.Ю., Подворчан Ю.А., Яруллина А.Р. Адаптация первокурсников к университетской жизни: факторы стресса и механизмы поддержки // Молодой ученый. 2015. - № 11 (91). С. 1362 - 1364.

10. Краснова В.В., Холмогорова А.Б. Социальная тревожность и студенческая дезадаптация // Психолого-педагогические исследования. 2011 №1. [Электронный ресурc]. URL: http://psyedu.ru/journal/2011/1/2060.phtml (дата обращения: 25.02.2021).

11. Крюкова Т.Л. Психология совладающего поведения в разные периоды жизни: монография. Кострома, КГУ им. Н.А. Некрасова: 2010.296 с.

12. Никитина И.В., Холмогорова А.Б. Социальная тревожность: содержание понятия и основные направления изучения // Социальная и клиническая психология. 2010. - №1. С. 80 - 85

13. Павлова Т.С., Холмогорова А.Б. Психологические факторы социальной тревожности в студенческом возрасте // Консультативная психология и психотерапия. 2011. - №11. С. 29 - 42

14. Тарабрина Н.В. Практикум по психологии посттравматического стресса. СПб. Питер, 2001. 268 с.

15. Холмогорова А.В., Гаранян Н.Г., Горшкова Д.А., Мельник А.М. Суицидальное поведение в студенческой популяции // Культурно-историческая психология. 2009. - №3. С. 101 - 110.

16. Carver, C.S., Scheier M.F., Weintraub J.K. Assessing coping strategies: A theoretically based approach // Journal of Personality and Social Psychology. 1989. V. 56, P. $267-283$.

17. Watson D., Friend R. Measurement of Social-Evaluative Anxiety // Journ. of Consulting \& Clinical Psychology. 1969. Vol 33 (4). P. 448 - 457. doi: http://dx.doi.

\footnotetext{
( Герасимова Оксана Юрьевна (oksana-5858@mail.ru), Семченко Любовь Николаевна (luba_sem96@mail.ru), Батуева Светлана Владимировна (batuevas@mail.ru).

Журнал «Современная наука: актуальные проблемы теории и практики»
} 